\title{
Lung Non-Small Cell Carcinoma
}

National Cancer Institute

\section{Source}

National Cancer Institute. Lung Non-Small Cell Carcinoma. NCI Thesaurus. Code C2926.

A group of at least three distinct histological types of lung cancer, including non-small cell squamous cell carcinoma, adenocarcinoma, and large cell carcinoma. Non-small cell lung carcinomas have a poor response to conventional chemotherapy. 